\title{
SIPHONING SEA WATER BACK INTO THE ENGINE IN FAST BOATS
}

\author{
Osman Azmi Ozsoysal \\ Department of Naval Architecture \& Marine Engineering, Istanbul Technical University, Ayazaga Campus, Maslak, \\ Istanbul, TURKEY, ozsoysal@itu.edu.tr
}

Follow this and additional works at: https://jmstt.ntou.edu.tw/journal

Part of the Transportation Engineering Commons

\section{Recommended Citation}

Ozsoysal, Osman Azmi (2010) "SIPHONING SEA WATER BACK INTO THE ENGINE IN FAST BOATS," Journal of Marine Science and Technology: Vol. 18: Iss. 4, Article 3.

DOI: $10.51400 / 2709-6998.1899$

Available at: https://jmstt.ntou.edu.tw/journal/vol18/iss4/3

This Research Article is brought to you for free and open access by Journal of Marine Science and Technology. It has been accepted for inclusion in Journal of Marine Science and Technology by an authorized editor of Journal of Marine Science and Technology. 


\section{SIPHONING SEA WATER BACK INTO THE ENGINE IN FAST BOATS}

\section{Acknowledgements}

This study is sponsored by the Turkey-Directorate General of Health for Borders and Coasts, Health Ministry of Turkish Republic to investigate the failure analysis of main engines of Ambulance/Health Boats. The author would like to extend cordial thanks to A. I. Karaş, M. Bekler, N. Nurali, F. Öke and F. Çolak for their helpful cooperation and collaborations. 


\title{
SIPHONING SEA WATER BACK INTO THE ENGINE IN FAST BOATS
}

\author{
Osman Azmi Ozsoysal*
}

Key words: water siphon, raw water, goose neck, wet-exhaust, exhaust back pressure.

\begin{abstract}
A failure investigation has been conducted on the exhaust system of a high speed marine diesel engine in Turkish ambulance boats. Premature failures were reported on the poor starting, on the loss of power, on the lubricating oil leakage and on the engine overload. It was observed some significant tracks of sea water found its way into the exhaust passages from condensation of the salt water vapour and also from entering some sea water into the exhaust system. In order to initiate a more accurate cause investigation, the engine went through an overhaul inspection, in which it was determined that there were corrosion and some deposits throughout the exhaust system. After performing the systematic cause analysis of the engine damage, it is concluded that erroneous design decisions cause to siphon sea water back into engine, doing expensive damage. Ever since water has been used to cool exhaust gases, there will be many cases of engines flooding with water from the exhaust system. Recognizing the potential problems mentioned in this paper, a wet-exhaust system is recommended to keep water out of all small and indoor marine propulsion engines.
\end{abstract}

\section{INTRODUCTION}

With the exception of some two-stroke cycled diesels and certain special applications, most marine diesel engine exhausts are water cooled and it is called as wet exhaust system. This is a common application in fast and small crafts. Water is drawn into the craft and circulated through the engine cooling jacket or engine coolant heat exchanger. Water is then injected into the exhaust to cool the combustion gases so that they might be safely discharged through the hull of craft without presenting any fire hazard. Accordingly, a marine exhaust muffler must handle not only exhaust gases, but also the waste cooling fluid or water which is injected into the exhaust sys-

Paper submitted 03/17/09; accepted 07/13/09. Author for correspondence: Osman Azmi Ozsoysal (e-mail: ozsoysal@itu.edu.tr).

*Department of Naval Architecture \& Marine Engineering, Istanbul Technical University, Ayazaga Campus, Maslak, Istanbul, TURKEY tem. A wet exhaust has several advantages over a dry exhaust. The injected water can lower the temperature of the exhaust gases from as high as $1,000^{\circ} \mathrm{C}$ to below $100^{\circ} \mathrm{C}$, cooling the gases sufficiently to allow the use of flexible hose after the water injection point. Flexible hose is easier to run than pipe, is not subject to corrosion or stress cracking; and absorbs the movement and vibration of a flexibly mounted engine. The water-cooled exhaust needs no insulation, and does not pose a fire or burn hazard to either the boat or crew. What's more, as the temperature of the exhaust gases falls, the volume of the gases declines proportionately, reducing exhaust noise. At the same time, the minimal exhaust back pressure generally needed to lift the exhaust water out of the boat also muffles the sound. This is a significant list of benefits. On the downside, ever since water has been used to cool exhausts, there have regularly been cases of engines flooding with water from the exhaust system. Problems occur because on almost all sailboats, and on many powerboats, the engine is installed below the waterline. Even if it's not below the waterline when the boat is at rest, the engine may well end up there when the boat heels, or when it is heavily loaded. This latter case can be particularly dangerous: because the boat's designer or engine installer may not have adequately planned for it. Erroneous design decisions, however, have frequently caused water to siphon back into engines, doing expensive damage and even sinking boats, so it is necessary to look at this subject in some detail.

Basic idea is to spray water into the exhaust gases as they exit the engine. The water then collects in the base of a muffler (silencer) until it blocks the exit pipe. At this point the exhaust pressure rises until it is high enough to drive the water out of the exhaust pipe. The silencers are mounted as close to the centreline of the boat as possible in order to reduce the risk of water surging back into the engine when the boat heels to extreme angles.

Dry exhaust is also another widespread application. Some naval architects and marine engineers prefer to utilize a goose neck form in the exhaust line in those cases. Sometimes there is no sufficient space below the engine to get the silencer low enough to keep the sea water out of the exhaust; the exhaust must be looped up to a point at which it creates excessive back pressure.

Unconventional goose neck applications produce a bad possibility to siphon the raw water into the main engine. When 
the engine is shut down, water flowing into the exhaust pipe or through the water-injection line will steadily siphon into the silencer then back up the exhaust pipe into the manifold. If any exhaust valves are open, usually the water steam is condensed throughout the exhaust manifold and passage, rarely some sea water is flowed to the cylinders and dribble down past piston rings into the crankcase.

All these possibilities and design concepts mentioned above are detailed in open literature [1-3, 5].

This paper studies the possible reason or reasons of this kind of failure and its effects on the damage size at high speed marine diesels in the Turkish ambulance boats. The ambulance/health boats, which are out of practice due to the engine failure, are special purposed, high speed crafts. Particular characteristics about boats are given in Table 1.

Main drive engines are a couple of high speed turbocharged marine diesels and their characteristics are shown in Table 2.

Original exhaust line configuration combined with the open-circuit sea-water cooling system is illustrated in Fig. 1. A goose neck arrangement is preliminary thought to prevent to lift the cooling-sea water. Beyond the water-injection point, good quality wire-reinforced steam hose is mounted. Transom stern dives into the depth a bit more than service condition during the highest speed. This can be clearly seen from the coloured region below the black thick line at Fig. 1 .

Engine room arrangement is overcome with some difficulties due to the narrow suitable area. Engine is mounted under the deck casing as shown in Fig. 2. Air intake is just after a couple of dry type filters which its openings are replaced directly towards to the machinery (engine) room.

Exhaust outlet position at the keel level of transom stern is shown in Fig. 3. A convenient number of zinc anode plates were placed next to the exhaust outlet. A circular steel tap plate was also placed at the mouth of the exhaust outlet.

Neither the cover plates, nor the goose neck prepared any appropriate solution in order to reduce the risk of sea water splashing back onto the inner surface of exhaust line and rusting them. Major problem is here that the sea water line is level with or above the exhaust pipe bend.

Several researchers introduced several ideas about preventing any raw water siphoning back to engine through exhaust outlet. United States Patent Office has just approved total 21 patent application since 1967. The first patent request proposes to discharge the sea together with the exhaust gas after decreasing its high temperature to an acceptable level [6]. The basic logic how it works can be clearly seen from the sketch in Fig. 4. The latest patent application [7] on same subject was confirmed in 2006.

Overall length of the small boats generally varies from 15 to 25 meters. Basic difficulty at the design stages of these boats is resulted from their small machinery spaces and this is inevitable.

Funnels whether coarse or slim are not desired to be used due to highly possible of unpleasant sight of boats. Other negativity of the classical funnel application needs the hot
Table 1. Design characteristics of an ambulance/health boat.

Main dimensions of Ambulance/Health Boats

\begin{tabular}{l|c}
\hline Total length & 17.75 meters \\
\hline Breadth & 4.19 meters \\
\hline Draught (design) & 1.20 meters \\
\hline Draught (cruising) & 0.90 meters \\
\hline Service speed (max) & 60 sea miles/hour \\
\hline Course distance & 300 sea miles \\
\hline Propulsion system & ASD12B1L Arneson \\
\hline Propeller & 2 screws \\
\hline
\end{tabular}

Table 2. Main engine characteristics according to the manufacturer data.

\begin{tabular}{l|c}
\hline \multicolumn{2}{c}{ Diesel engine characteristics } \\
\hline Power output (max) & $810 \mathrm{~kW} / 1086 \mathrm{bhp}$ \\
\hline Speed (max) & $2450 \mathrm{rpm}$ \\
\hline Specific fuel consumption (full load) & $216 \mathrm{~g} / \mathrm{kWh}$ \\
\hline Reduction ratio & $1.2-2.5$ \\
\hline No. of cylinder & 8 \\
\hline Bore/Stroke & $135 \mathrm{~mm} / 156 \mathrm{~mm}$ \\
\hline Displacement, total & 2.23 litres \\
\hline
\end{tabular}

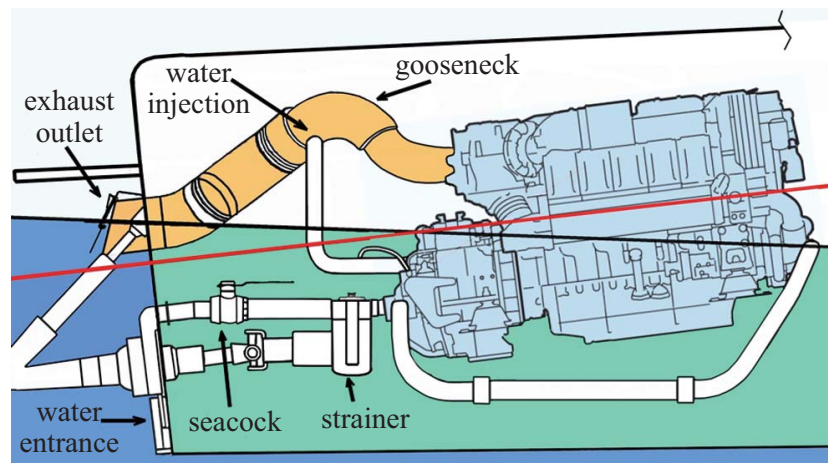

Fig. 1. Exhaust line and cooling sea water arrangement of ambulance/ health boat.

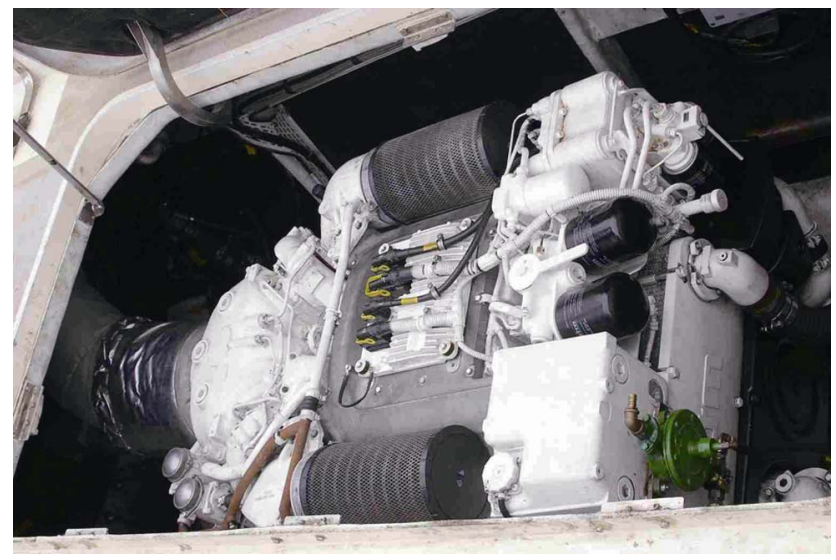

Fig. 2. Looking at the machinery room. 


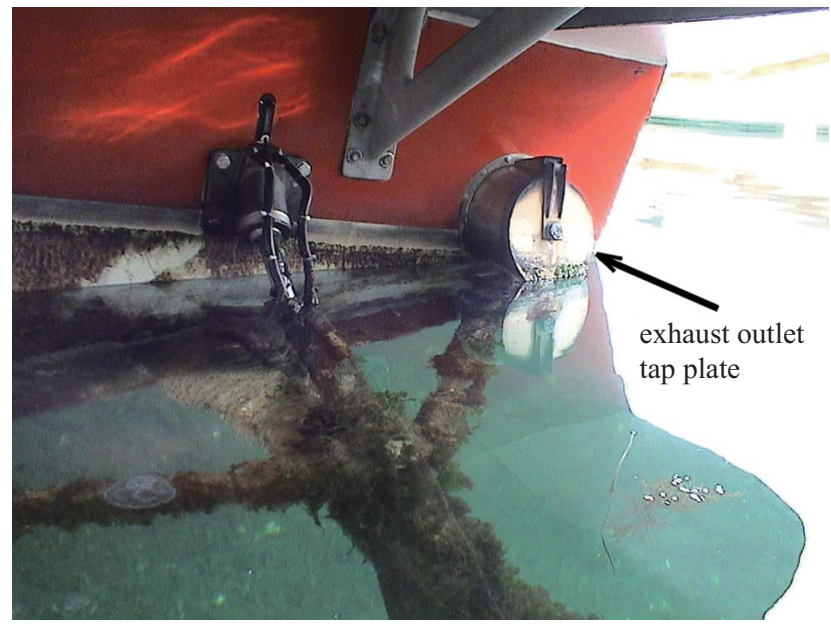

Fig. 3. External view of the ransom stern and the exhaust outlet.

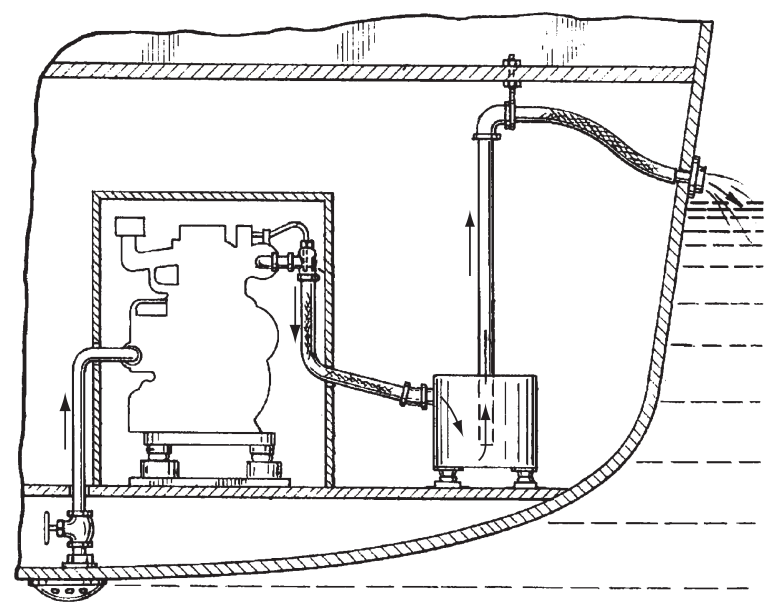

Fig. 4. The first idea on the wet exhaust for small crafts [6]. pipes passing inside the accommodation spaces towards the funnel and produce a risk decreasing the comfort level. Further thought against to the standard funnel application is the possibility of sprinkling the soot particles from the funnel over the air open deck. Consequently, the designer does not like to use any classic funnel. Naval architects generally prefer to throw away the water cooled exhaust from any imperceptible point next to the water line. Underside of the swimming platform at the stern of motor boat is the best appropriate place for this aim. This choice also helps to take the bad smell away from the boat due to the sulphur content in fuels.

However, the designers have another handicap to overcome. They should reach to a decision about much more suitable goose neck form at a point before mixing the sea water to the exhaust line. Basic idea is to prevent to siphon the raw water or sea water back into the engine. Standard goose neck form is generally deformed up to nearly smooth by the designers since they don't accept to make the open air deck area small and because they try to prevent any hillock on the stern deck when the water draught is small or the height of machinery room is short. Wet muffler is just then the last and only solution to prevent siphoning the sea water back into the engine.

The designers have unfortunately a further problem dealing with any possibility to achieve higher levels for exhaust back pressure. Most boat manufacturers don't risk to be bothered with high exhaust back pressure problem. Many fast boats all over the world are generally produced without having any wet muffler. Their manufacturer cannot care to give necessary importance which kind of problems the fast boats will encounter after the sale or when the boats are staging. Turkish ambulance boats were produced with a nearly smoothened goose neck on their exhaust line. Manufacturer's primary thought is that the exhaust gas pressure would prevent siphoning sea water back into the engine. Boat's designer did not have any idea about the boat personnel's habits and how running the engine. Major handicap here is the engines to be stopped immediately after landing to quay. After a long cruise, the excessive sea vapour/mist can rapidly reach throughout the exhaust lines when the boat engineer stops the engine without permitting to run the engine at idle speed for a while, for example approximately 5 minutes.

Besides of all these facts, the circular tap plate at the exhaust outlet did not help to prevent to flow the sea water into the exhaust line. Slight agitation on the sea surface also caused entering some more water into the exhaust line. When all these negatives came together, the engines met to face with their catastrophic hazardous.

Machinery alarm signals, engine malfunction and damage size always offer important clues about the perfect reason of any investigated engine failure. This work deals with a siphoning raw water back to the engine and is hoped to be an enlightening guide for the naval architects, marine engineers and researchers to overcome this kind of their problems. In this failure investigation, the machinery alarm signal denotes the low oil level, engine overload, loss of power. Other symptoms are the poor starting, small leakages of lubricating oil at several point on engine (specially around of the oil dipstick pipe). In order to initiate a more accurate cause investigation, the engine went through an overhaul inspection. It was initially observed some significant tracks of sea water found its way into the exhaust passages from condensation of the salt water vapour and also from entering some sea water into the exhaust system. Corrosion remark and some deposits throughout the exhaust were determined. After performing the systematic cause analysis of the engine damage, it is concluded that erroneous design decisions cause to siphon sea water back into engine.

\section{PHYSICAL EXAMINATION AND REMARKS}

Noteworthy corrosion signs are observed along the exhaust line due to the water surging back into the engine. Rusting is generally outcome from the risk of sea water splashing. Exhaust outlet tap could not prevent to flow the sea water back 


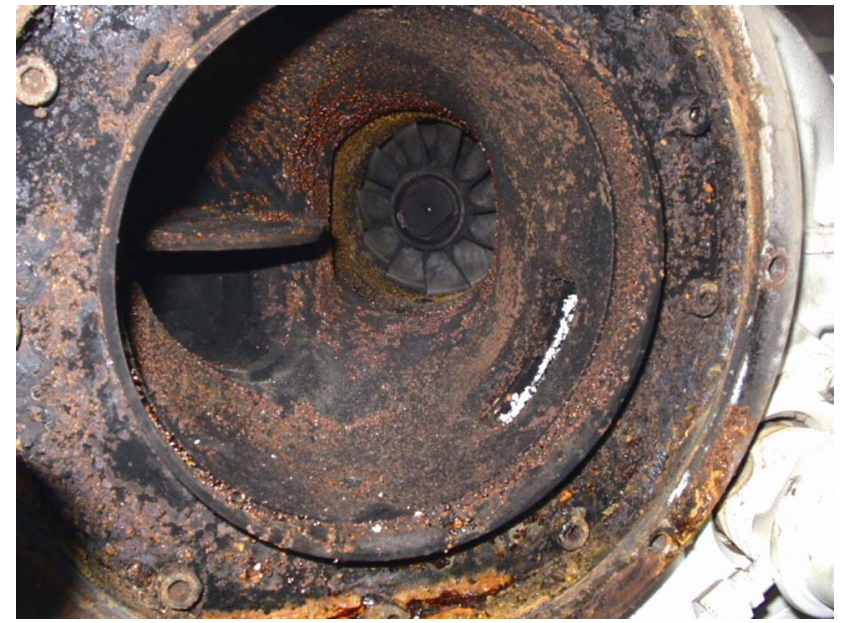

Fig. 5. Rust and corrosion signs at the exhaust turbocharger outlet.

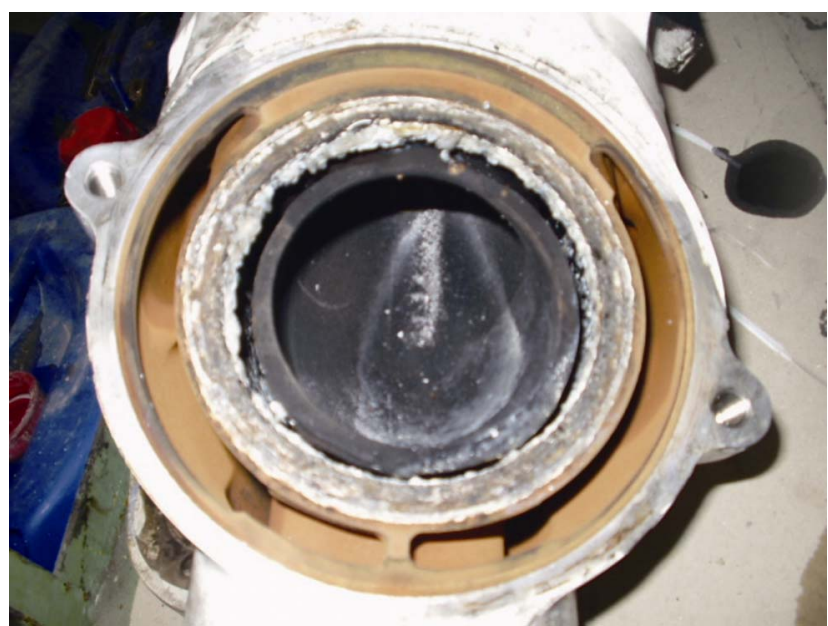

Fig. 6. Sea salt, mildew and less rusting before the turbocharger inlet.

into the engine due to the pitching movement.

Figure 5 shows the penetration size of rusting at the exhaust turbine outlet due to the water surging back into engine when the boat heels to extreme angles.

Rusting was observed to be diffused widely throughout the exhaust manifold. Because sea water vapour met the enough time to be condensed immediately after stopping the engine without running at idle speed for a while. When shutting down the engine whatever water vapour was in the pipes condensed and turned back into a liquid. On short trips, the sea water never had a chance to get hot enough to turn back into vapour and just stayed in the system and rust away the pipes. Some contours of sea salt because of the evaporation and some mildew remains can be easily seen in Fig. 6.

Connecting pipes between the cylinder heads and exhaust manifold, which is in fact simple cast iron unit, were so rusty that could not be re-used and repaired. As shown in Fig. 7, the tightening bolts are also worn because of the corrosion and the rusting.

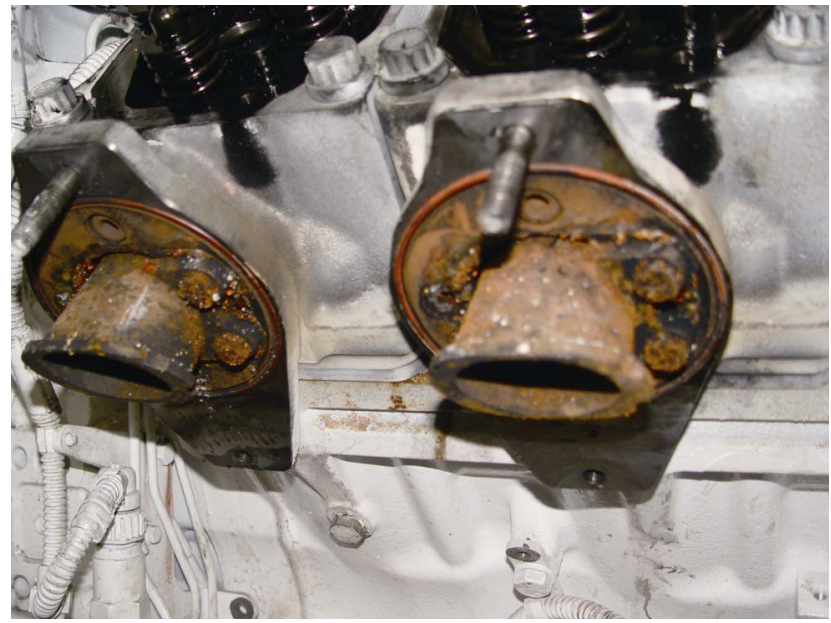

Fig. 7. Appearance of widely diffused rusting at the exhaust passages.

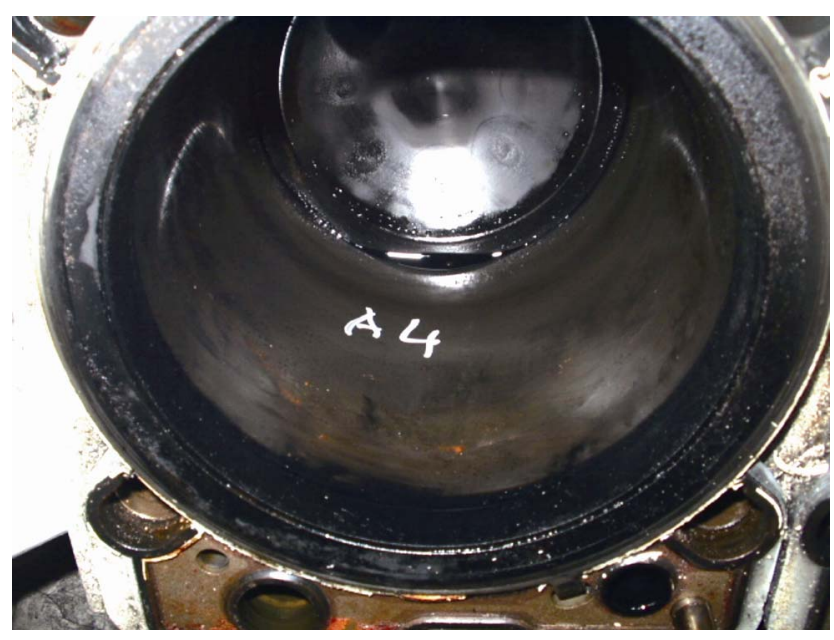

Fig. 8. Local rusting on the liner's inner surface.

It was noticed less amount of surface rust on liner, as shown in Fig. 8. This hazardous was noted at the cylinder no. 4 of block " $\mathrm{A}$ " which is nearest one to the exhaust turbocharger. In other words, some of the vapour got a chance to reach to the combustion bowl without condensing earlier. Some exhaust valves, which remained open after stopping the engine, played a major role and accelerated the event. So, the condensate caused the surface rust. A sample of lubricating oil was tested at an accredited laboratory and then no water leakage or evidence is observed from the lubricating oil analysis. The riser gaskets were also found without suffering any damage.

Exhaust valves of cylinder no. 4 were found to be intensively affected by the sea salt and the rusting. The sea water evaporated and leaved the salt crystals on the exposed surface of an exhaust valve because of the gas flowing at high temperatures. Overtime, the crystals caused rust to form. When the valve became sticky, it caused more water to be drawn backward from the exhaust elbow discharge into the engine. Figure 9 shows the rusty exhaust valves numbered 1 and 2 . 


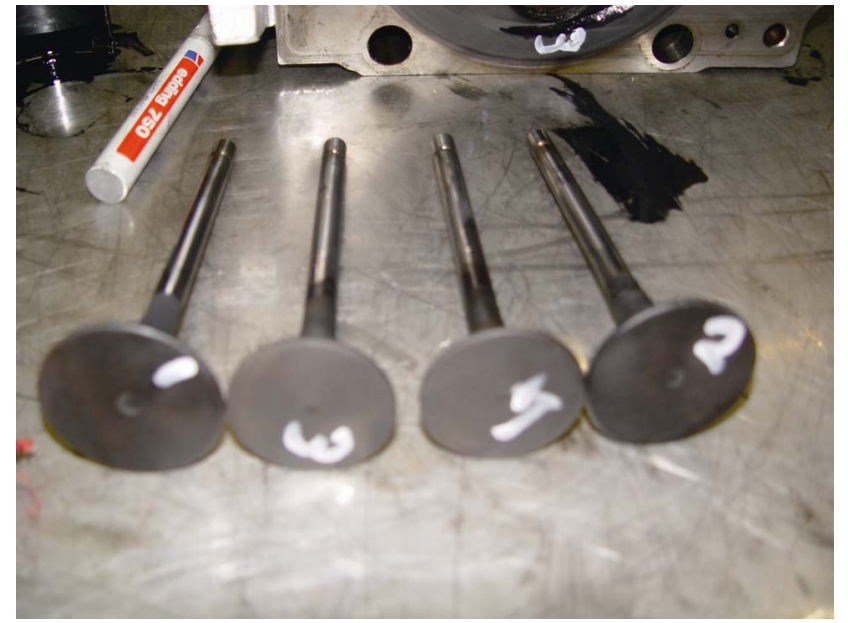

Fig. 9. Less evidence of rusting on the exhaust valve skirts.

It was also observed similar salt contours on the piston crown just across the exhaust port skirts. Abnormal temperature distribution and bad fuel injection caused the remarkable pitting on piston crown as shown on Fig. 10. Compression ring collar and grooves just above the gudgeoned pin were seemed to be damaged due to the abnormal heat absorption. Side part of the piston crown was even found to be melted.

\section{DISCUSSION AND RESULTS}

Throughout the history of engineering, reliability improvement (also called reliability growth) arising as a natural consequence of the analysis of failure has long been a central feature of development. This 'test and correct' principle had been practised long before the development of formal procedures for data collection and analysis because failure is usually self-evident and thus leads inevitably to design modifications. Nineteenth- and early twentieth-century designs were less severely constrained by the cost and schedule pressures of today. Thus, in many cases, high levels of reliability were achieved as a result of over-design. The need for quantified reliability-assessment techniques during design and development was not therefore identified. Nowadays, it is necessary to input component failure modes into the fault tree or failure mode analyses for addressing the specific system failures.

Design philosophy needs to cover three factors such as the complexity, the duplication/replication and the excess strength due to the longevity. In this case, failure symptoms did not denote any complexity since the failure case could arise from a combination of drift conditions rather than the failure of a specific component. It is also well known that the complexity of any modern engineering products and systems ensures the system failure not to follow simply from any component part failure. Reliability prediction techniques are mostly confined to the mapping of component failures to system failure. It is therefore less likely to be foreseen by the designer. The use of

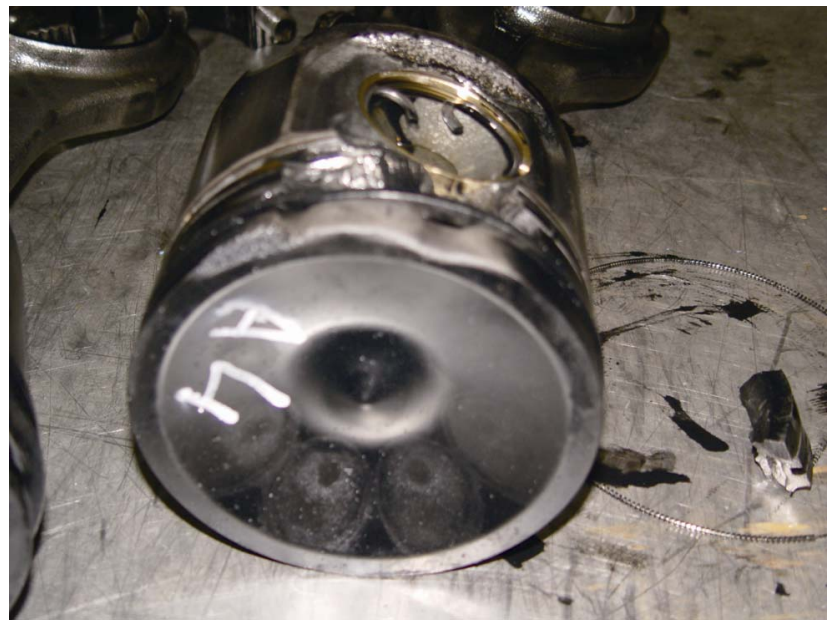

Fig. 10. Pitting and sea salt contours on piston crown.

additional, redundant, parts whereby a single failure does not cause the overall system to fail is a frequent method of achieving reliability. This is defined as duplication or replication method. Last method is the excess strength and it confirms the deliberate design to withstand stresses higher than are anticipated will reduce failure rates. The last two of the mentioned methods are costly. The cost of reliability improvements needs to be paid for by a reduction in failure and operating costs. This argument is not quite so simple for hazardous failures but, nevertheless, there is never an endless budget for improvement and some consideration of cost is inevitable.

On the other hand, the design targets should cover contractual requirements which can include both assessment of the design and demonstration of performance. In this investigated Turkish ambulance boats' failure case, the contractor could not wholly determined the design requirements, because the high speed boats would be the pioneer examples at service at the Turkish Bosporus. Technical experience at contractor side was also clearly insufficient and incapable. Designer of the boats planed the boats to be used in the coast guard and the custom control. At that time, the ambulance boats were the new version of those with a small scaled arrangements in the accommodation spaces.

Ambulance boats still serve under the convention of EU Council Directive 92/29/EEC of 31 March 1992 on the minimum safety and health requirements for improved medical treatment on board vessels [4]. For this reason, the ambulance boats need more manoeuvring than the other official boats and they also have to run under more unstable sea conditions and more bad weathers than other official boats. Ambulance boats are charged an important duty for the human health. Unfortunately, their operational characteristics were not appreciated during the design stage. Hence the reliability and the risk analysis etudes fail at the pre-design and design stages of the boats and at the end the unexpected catastrophic damage comes true. 
A methodological approach, which is applicable during the final stage of a new ferryboat design to foresee its service availability to improve maintenance policies and fleet management, is introduced by Vivalda and Capizzi [8]. Their method applied the Monte Carlo simulation based on reliability block diagrams and maintenance plans. Fast ferries and fast patrol boats or ambulance boats differs from each other. Ambulance boats are the high speed crafts for carrying out the patients from transit ships. Boats have a sliding characteristics at high speed while its back dives some more into sea. Slamming of the craft bottom at high speeds and at bad sea conditions causes fast oil vaporization in crankcase, oil mist and high oil pressure. Extra back pressure can probably not to be too much. Big concerning here is the back-siphoning when the diesel engine is not running or during the astern manoeuvring. Exhaust back pressure was regularly measured to be sharply increased with diving the exhaust outlet more into underwater.

In this study, the root cause analysis (RCA) method was utilized instead of the fault tree analysis (FTA) method. Because RCA aims to identify the root causes of design. Root cause analysis is very effective method to solve by attempting to correct or eliminate root cause, as opposed to merely addressing the immediately obvious symptoms. It is highly possible the likelihood of problem recurrence to be minimized by directing corrective measures at root causes. However, RCA is generally considered to be an iterative process and is frequently viewed as a tool of continuous improvement.

All evaluations and judgements were taken up with a large group participated by the engine service authorities, dockyard engineers, representatives of boat designer and some officials under presidency of the author. Commercial expectations, anxieties and current status of the boats do not permit to discuss more in detail according to the general compromising of confidential decision. However, the symptoms and damage size will be enough to realize how a missing factor during the design stage or how the capability of designer or how an insufficient contract edict affects the longevity and also the failure possibility.

Failure investigation showed that the boat crew followed the operating and maintenance instructions requested by manufacturer, moderately. Replacement and spares strategies were also out of subject because the engines were all new. Material properties were common, familiar and standards. Present clues and inferences then just focused on a crucial point which is the last and only area dealing with the design reliability and safety.

It would be helpful to remember and recheck, here, the failure signals, symptoms and records, again. Boat engineers first recorded the high oil pressure, the less oil leakages at sealing and the overloading when boats were attended. Machinery alarm signals denoted low oil level, overload and loss of power. Other symptoms indicates the poor starting. Boat crew also observed some leakages of lubricating oil from several point on engine. Oil leakages were light yellow colour

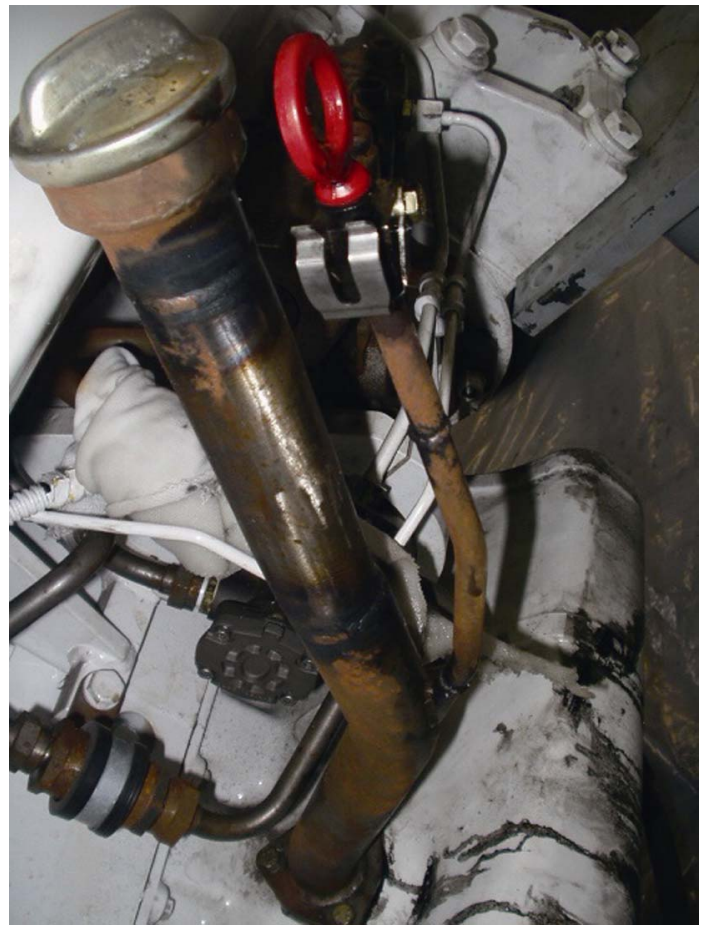

Fig. 11. Oil dipstick pipe, its clips and oil mess.

on the top side of engine. Less oil leakages were seemed around the seals between cylinder head and engine block, around of the injectors due to the high oil temperature and high pressure. Dirty oil leakages were specially concentrated near by the crankcase, around of the oil dipstick pipe. These were because of the high oil pressure in crankcase due to the much oil mist. First precaution against to the failure was to add a clip to the oil dipstick to prevent removal from the oil dipstick pipe. Figure 11 shows the current condition of oil dipstick pipe, its clips and oil mess. Further regulation was introducing of a check valve at the charge air intercooler which will allow the oil drainage during idle and no operation and that would be closed with increasing the charge air pressure. Crankcase ventilating circuits were also controlled and oil pressure was gauged. Crankcase ventilating filters were changed with new type of one's due to the clogging. However, all these arrangements were not just right solutions for preventing the irrevocable hazardous.

Early failures were reported on the poor starting, loss of power, oil leakage and overload. These were also harmonious with high oil pressure and high oil temperature. Boat crew also observed some intensive and black smoke with trail at the exhaust outlet when the boats were cruising at high speed mode and leaving from the port. Figure 12 shows the grayblack coloured exhaust and opening of outlet tap while the boats are just leaving from the pier. Diesel engines could not rise up to high speeds. Boat crew and engine serviceman had the injectors rebuilt and checked again. Everything was seemed to be tolerable. Air filter was also at a good condition and there was no blockage. Cooling systems was checked and 


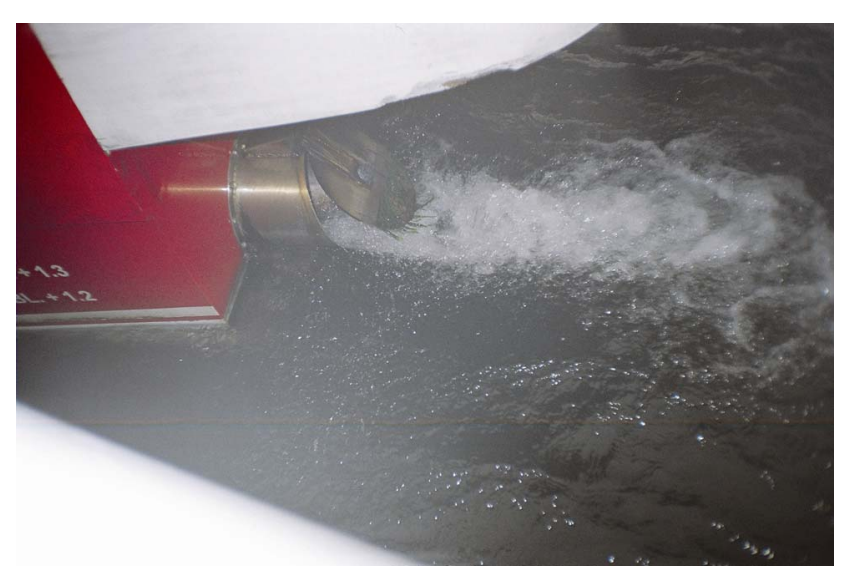

Fig. 12. Opening of the exhaust tap and black smoke.

found out continuing on its normal running procedure. Finally, the overload symptoms pointed out as last alternative, i.e. the turbocharger. In other words, faulty turbocharger did not provide enough mass flow rate of charge air to the diesel cylinders. Turbochargers have two stages and their second stage could not be of service due to severe rusty layers on the shutter of automatic butterfly valve.

Exhaust outlet tap was another source of failure and it was incapable to prevent flowing the raw water back into the engine. The tap is mounted at the top of the outlet pipe with a simple hinge, so it could just be controlled by a soft spring. Although a goose neck form was employed on exhaust line after the turbocharger, its form was improper since it had a slightly rounded elbow shape. Besides the junction point of hot exhaust and sea water was inappropriate. As shown in Fig. 1, the geometric form (slope) of goose neck could not help to prevent flooding some sea water through the former segment of exhaust line. Whereas the junction point should be selected to set at the lower skirt of the goose neck to cut down the mist formation. These all increase the possibility of water flooding through the turbocharger. General form of exhaust line, as shown in Fig. 1, gives important clues to explain how this kind of hazardous happens in the ambulance boats. Even if the exhaust outlet was normally above the waterline, water siphoned into a heeled or well-laden boat, as mentioned previously. It was boosted the exhaust pipe by high seas; or, in an otherwise calm anchorage, be forced up the pipe by repeated wakes from passing boats. This phenomenon is known as water hammer.

Engineers in ambulance boats usually stopped the diesel engines immediately whenever the ambulance boats were staging to pier or in marina. Since the boat engineers did not permit to run the engines for a while after landing, for example minimum 5 minutes at idle speed, the hot exhaust gases could not find any enough time to cool itself regularly. So the inner surface temperature of exhaust line was still kept at high levels despite of the gas temperature was sharply dropped due to the no exhaust. This offered some inevitable pressure drops inside the exhaust pipe. Design concept of cooling the exhaust gas with washing sea water brings out some unexpected and extra condensation of sea water vapour. It seems like positive pressure is necessary, possibly to avoid dissolved gases from coming out of solution.

Repeated cranking of a difficult to-start engine also pumped excessive water into an exhaust. With every cranking attempt, the raw-water pump moved more water into the exhaust. That water could not be pumped out until the engine fired by which time, there might be enough water in the exhaust to flood the engine.

Sea salt residues and tracks proved all these considerations and judgements. One can say that the main reason of the high speed ambulance boats is the siphoning the sea water back into the diesel engine.

Recognizing those potential problems mentioned above, one can say that a wet-exhaust system must be designed to keep water out of all engines. A water-lift system should be designed to prevent siphoning through the raw water pump when the engine is stopped. If this is accomplished through the use of a siphon break device, it shall be installed at the top of a loop that shall rise high enough to assure that the high point where the siphon break device is installed will always be above the water level surrounding the boat.

Depending on the design of the boat, the condition of its loading and the sea conditions encountered, this loop must be at least 0.5 meter above the water line at repose. The siphon break point must also be arranged at 0.2 meter above the water line.

Unconventional goose neck application cause an expensive damage on the diesel engines of ambulance boats. There are four ambulance boats serving in Turkish straits. Each boats have two diesel propulsion engines and each diesel also have eight cylinders in "V" type block. Failure caused so a damage as each diesels turned into unserviceable. In other words, whole liners, pistons, injectors, exhaust and inlet valves, exhaust manifold and turbocharger were needed to be changed after dismantling each diesel. Repair cost of each diesel is nearly 85 percent of a new one. Total repair cost of all boats passes over nearly 2 million US dollar. This is rather dramatic and needs to think on the engineering spiral for improving the design, once more time, again and again. If any wet muffler has been mounted to the exhaust line in the ambulance boats, it would have cost approximately 10 thousands US dollar for each boat and it would have never been this kind of catastrophic damages in boats.

\section{CONCLUSION}

In this study, the failure analysis of a high speed marine diesel engine in Turkish ambulance boats is investigated. Engines are classified to be light duty, high performance engines by their manufacturer. Failure symptoms were the poor starting, loss of power, oil leakage and overload. It was also observed some significant tracks of sea water found its way into the exhaust passages from condensation of the salt water 
vapour and also from entering some sea water into the exhaust system.

When the failure symptoms, engine alarm signal, failure reports, engine journal records, manufacturer instructions, operational conditions of ambulance boats, damage size and its locations in diesels are altogether evaluated in a systematic cause analysis, it is recognized that the failure in Turkish ambulance boats is raised from siphoning the sea water back into engine. Failure is based on the unconventional "goose neck" configuration on the exhaust line. Exhaust system is not capable to prevent sea-water from flowing back into the engine. Recognizing the problem introduces to be used a wetexhaust system to keep water out of all engines. A water-lift system will be a good solution to prevent siphoning through the raw water pump even if the engine is stopped.

\section{ACKNOWLEDGMENTS}

This study is sponsored by the Turkey-Directorate General of Health for Borders and Coasts, Health Ministry of Turkish Republic to investigate the failure analysis of main engines of
Ambulance/Health Boats. The author would like to extend cordial thanks to A. İ. Karaş, M. Bekler, N. Nurali, F. Öke and F. Çolak for their helpful cooperation and collaborations.

\section{REFERENCES}

1. Ajootian, C., Engine Blocks Choke on Water, Boat/US Magazine, January (2003).

2. Calder, N., Marine Diesel Engines, Maintenance Troubleshooting and Repair, $2^{\text {nd }}$ ed., International Marine, Camden, Maine (1992).

3. Compton, P., Troubleshooting Marine Diesels, $4^{\text {th }}$ ed., Mc-Graw Hill \& International Marine (1997).

4. Council Directive 92/29/EEC of 31 March 1992 on the minimum safety and health requirements for improved medical treatment on board vessel, 31992L0026, Official Journal L 133, 30/04/1992, pp. 19-36 (1992).

5. Traister, J. E., Marine Engine Troubleshooting and Repair, Prentice Hall, Englewood Cliffs, NJ (1987).

6. US Patent, Exhaust and muffling system for marine engines, US3296997, (1967).

7. US Patent, Exhaust system with an integral moisture trap, US7065961, (2006).

8. Vivalda, C. and Capizzi, S., "Availability analysis of high speed crafts: A way to improve competiveness," Proceedings of the International Offshore and Polar Engineering Conference, ISOPE, v 4, p. 544-548 (1999). 